\title{
ANÁLISE POSTURAL DE OPERADOR AGRÍCOLA NA ATIVIDADE DE PREPARO DO SOLO EM ÁREAS DE VÁRZEA
}

\author{
Luan Pierre Pott ${ }^{1}$, Juliano Depoi ${ }^{1}$, Airton dos Santos Alonço ${ }^{1}$, Gessieli Possebom ${ }^{1}$, Tiago Gonçalves Lopes ${ }^{1}$, Rafael Sobroza Becker ${ }^{1}$, \\ Dauto Pivetta Carpes ${ }^{l}$, Gabriel Donato ${ }^{1}$ \\ ${ }^{1}$ Departamento de Engenharia Rural, Universidade Federal de Santa Maria, 97105-900, Santa Maria, Brasil.
}

*E-mail: luanpierrepott@hotmail.com

\section{RESUMO}

O trabalho do homem, quando executado de forma exaustiva, pode trazer consequências prejudiciais ao seu corpo, pela exigência física, esforços transmitidos pelos equipamentos e, principalmente, pela postura necessária para o desenvolvimento de uma determinada atividade. Com isso, o objetivo do trabalho foi avaliar as posturas realizadas durante a jornada de trabalho de um operador de trator agrícola na atividade de preparo do solo em área de várzea. Para a coleta de dados, foi realizado o acompanhamento da atividade em uma propriedade rural, no município de Ivorá - RS, por meio de registros fotográficos das posturas do operador ao longo da jornada de trabalho diária, além da contagem do número de viradas do operador para trás e o tempo em que permanecia nessa posição. A análise postural foi efetuada com os métodos $O W A S$, RULA e REBA, sob uso do software Ergolândia 6.0. As análises permitiram observar que as posturas de rotação do tronco para trás diminuíram ao longo da jornada de trabalho e foram impulsionadas, possivelmente, pela fadiga ocasionada pelo trabalho. Ainda, a análise geral dos métodos demonstraram a necessidade de intervenção ergonômica à curto prazo, como o apoio de membros superiores durante a realização da tarefa.

Palavras-chave: Ergonomia. Métodos. Intervenção.

\section{Introdução}

O desenvolvimento tecnológico, na busca por novas máquinas, visa aprimorar a relação homem-máquina, de forma que seja imposta ao homem uma carga de trabalho mais suave, proporcionando, sobretudo, o aumento da produção e a redução da fadiga aos trabalhadores. Nos últimos tempos, vêm sendo desenvolvidos estudos procurando facilitar a relação do homem com o ambiente de trabalho [1-2].

Os operadores de tratores agrícolas estão sujeitos a vários riscos durante a execução de suas atividades, tais como: posições desfavoráveis, ruído, poeira, calor e vibrações. Dessa forma, o trabalho do homem, sob as condições já citadas, pode trazer consequências prejudiciais ao seu corpo pela exigência física e esforços transmitidos pelos equipamentos.

Ademais, os tratoristas possuem dificuldade em manter uma postura estável e ereta, devido à estrutura da máquina agrícola e da necessidade, em muitos casos, do controle simultâneo da direção (para frente) e do trabalho que está sendo executado (na parte traseira) [3]. Isso pode ser evidenciado, por exemplo, no preparo do solo, considerado por Pauluk; Michaloski [4] como uma atividade desgastante.

Possebom [5] em estudo de comparação de métodos e análise postural em operador de preparo de solo, concluiu que apesar dessa atividade ter apresentado baixo risco ergonômico, são necessários alguns estudos mais aprofundados, tendo em vista a complexidade e a especificidade dessa operação.

A principal atividade dos operadores dessas máquinas é realizada no posto de condução na cabine e, por isso, a importância da aplicação de critérios ergonômicos que permitam estabelecer a correta adaptação dos componentes do sistema homem-máquina [6]. Para tanto, é preciso levar em consideração as características dos operadores e do trabalho realizado, para que possa ser obtida a maior eficiência produtiva, bem como o maior grau de conforto e segurança na tarefa, proporcionando melhores condições de trabalho.

Segundo Iida [3] a ergonomia é o estudo sobre o relacionamento entre o homem e seu trabalho e do equipamento e ambiente. Numa situação ideal, a ergonomia deve ser aplicada às etapas iniciais do projeto de uma máquina, ambiente ou local de trabalho, visando sempre o conforto e segurança do operador. 
Segundo a Associação Brasileira de Ergonomia [7], a ergonomia é uma forma de otimizar o bem-estar humano e o desempenho global do sistema.

De acordo com Santos e Fialho [8] a análise ergonômica do trabalho (AET) pode ser subdividida em três fases: análise da demanda, análise da tarefa e análise das atividades. $\mathrm{Na}$ análise da demanda é realizada a definição do problema a ser avaliado com os atores em questão, ao passo que a análise da tarefa considera as condições técnicas, ambientais e organizacionais ea análise das atividades proporciona a visualização e avaliação do trabalho que é efetivamente executado pelo trabalhador, bem como o seu comportamento.

Desse modo, o objetivo do trabalho foi avaliar as posturas realizadas durante a jornada de trabalho de um operador de trator agrícola na atividade de preparo do solo em área de várzea, a fim de caso necessário, realizar uma intervenção de melhoria.

\section{Metodologia}

O estudo foi realizado no município de Ivorá - RS, numa área onde há o cultivo do arroz irrigado, em que o responsável é um produtor rural, cuja área de posse está localizada a 29³1'10' S e 5331'40' O, com altitude média de $83 \mathrm{~m}$. O solo predominante do local era o Planossolo Háplico Distrófico típico [9].

As avaliações ocorreram em maio de 2018, durante a operação de preparo do solo, que foi realizada com uma gradearadora de 9 discos acoplada em um trator Massey Ferguson ${ }^{1}$ 4275 com $75 \mathrm{CV}$ de potência. O trator com o equipamento percorria distâncias de 200 metros até realizar o retorno e seguir na faixa adjacente. A velocidade média de trabalho foi de $8 \mathrm{~km}$ $\mathrm{h}^{-1}$.

A análise postural foi desenvolvida através do acompanhamento de uma jornada de trabalho (08:00h até 12:00h), em que foi verificado o tempo de permanência em cada postura empregada para realização da atividade. Posteriormente, para captura das imagens, foi utilizada a câmera fotográfica do celular modelo Moto G5 ${ }^{1}$, com 13 megapixels, obtendo resolução das imagens de 4160 x 3120 pixels.

A partir desses dados, a análise postural foi efetuada com o auxílio de ferramentas ergonômicas que compreendem a observação das atividades do operador em seu local de trabalho, com captação de imagens estáticas. Foram adotados os métodos: Ovako Working Posture Analysing System (OWAS), Rapid
Upper Limb Assessment (RULA) e Rapid Entire Boby Assessment (REBA), através do software Ergolândia 6.0, 2018.

Pelo método $O W A S$ foram avaliadas as posturas das costas, braços, pernas e a atividade desenvolvida. Os resultados geram um código e são analisados em uma tabela descritiva (Tabela 1).

Tabela 1 - Descrição das categorias de ação do método $O W A S$.

\begin{tabular}{cc}
\hline Categorias & Nível de intervenção \\
\hline $\mathbf{1}$ & Não são necessárias medidas corretivas; \\
$\mathbf{2}$ & São necessárias correções em um futuro próximo \\
$\mathbf{3}$ & São necessárias correções tão logo quanto possível \\
$\mathbf{4}$ & São necessárias correções imediatas \\
\hline
\end{tabular}

Fonte: Adaptado de Ergolândia 6.0 (2018).

O método RULA foi utilizado para a avaliação da exposição do trabalhador aos fatores de risco que podem ocasionar os transtornos nos membros superiores do corpo. Para isso, foi avaliado o posicionamento de braço, antebraço, punho, rotação do punho, pescoço, tronco e pernas, além de considerar a atividade que seria executada.

Cada fator avaliado recebe uma pontuação de acordo com a postura, de forma que seja obtido, como resultado final, um escore de 1 a 7, sendo enquadrado em 4 classes de níveis de ação, conforme a Tabela 2 .

Tabela 2 - Pontuação geral para determinação do nível de intervenção ergonômica do método RULA.

\begin{tabular}{ccc} 
Nível & Pontuação & Nível de intervenção \\
\hline $\mathbf{1}$ & 1 ou 2 & Postura aceitável \\
$\mathbf{2}$ & 3 ou 4 & $\begin{array}{c}\text { Deve-se realizar uma observação. Podem ser necessárias } \\
\text { mudanças. }\end{array}$ \\
$\mathbf{3}$ & 5 ou 6 & $\begin{array}{c}\text { Deve-se realizar uma investigação. Devem ser } \\
\text { introduzidas mudanças. }\end{array}$ \\
$\mathbf{4}$ & 7 & Podem ser introduzidas mudanças imediatamente. \\
\hline Fonte: Adaptado de MCATMNEY \& CORLETT [10].
\end{tabular}

Também foi utilizado o método $R E B A$, que é semelhante ao RULA e compreende uma ferramenta responsável pela avaliação dos membros superiores e dos trabalhos com movimentos repetitivos, mas que possui seu enfoque nos membros inferiores. A avaliação de risco também é feita a partir de uma observação sistemática dos ciclos de trabalho, pontuando as posturas do tronco, pescoço, pernas, carga, braços, antebraços e punhos. A pontuação final gera um escore e,

\footnotetext{
${ }^{1} \mathrm{~A}$ citação de marcas e modelos comerciais não implica nenhuma forma de aprovação ou recomendação por parte dos autores.
} 


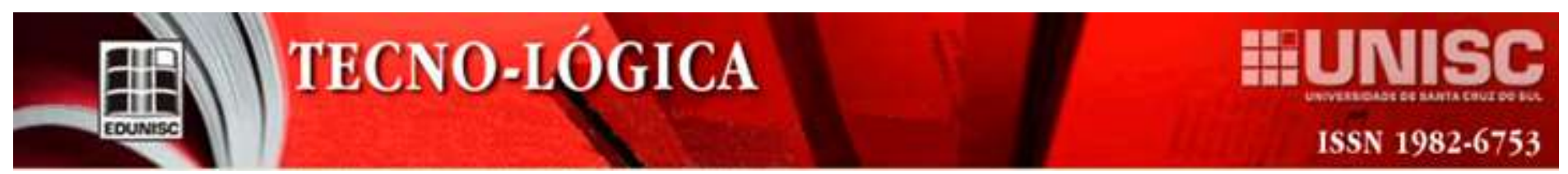

consequentemente, um nível de intervenção, conforme a Tabela 3.

Tabela 3 - Pontuação geral para determinação do nível de intervenção ergonômica método REBA

\begin{tabular}{ccc}
\hline Pontuação & Significado & Nível de intervenção \\
\hline $\mathbf{1}$ & Risco insignificante & Não é necessária \\
$\mathbf{2}$ ou 3 & Risco baixo & Pode ser necessária \\
$\mathbf{4}$ a 7 & Risco médio & Necessária \\
$\mathbf{8}$ a 10 & Risco alto & Necessária o quanto antes \\
$\geq \mathbf{1 1}$ & Risco muito alto & Necessária imediatamente \\
\hline
\end{tabular}

Fonte: Adaptado de Ergolândia 6.0 (2018).

Posteriormente, foi realizada a sumarização dos métodos de análise da postura do operador para a recomendação de intervenção de melhoria, caso seja apontada como necessária pelos métodos.

Também foi realizada a contagem de viradas do operador para trás, com intuito de visualizar o implemento, bem como o tempo que o operador permanece nessa posição. Essas avaliações foram realizadas durante 2 horas de trabalho.

\section{Resultados e discussões}

$\mathrm{Na}$ atividade de preparo do solo em área de várzea, foi verificada a predominância de duas posições. Na primeira posição, o operador encontra-se sentado, olhando para frente, com a coluna encostada totalmente no banco e com as mãos firmadas no volante do trator, conforme a Figura 1A. Na segunda posição, o operador observa a atividade executada na traseira do trator, rotacionando o tronco, conforme a Figura 1B. Esses resultados corroboram com o que é evidenciado por Possebom [5], em relação ao predomínio de duas posições durante a operação de preparo do solo com trator agrícola.

Durante a operação de preparo de solo, o operador permanece com ambos os braços sobre o volante, mas sem apoiar o antebraço. $\mathrm{O}$ apoio de um segmento corpóreo durante uma atividade, seja temporário ou permanente, é muito importante para evitar dor ou desconforto nos trabalhadores [10].

Nesse tipo de tarefa, a postura sentada é inerente [11], requisitando atividade dos músculos dorsal e ventral [3]. Embora a postura sentada seja considerada menos danosa do que a em pé, os operadores têm seus movimentos restritos, de forma que não conseguem realizar o alongamento dos membros e tronco.

Essas circunstâncias, segundo Dul e Weerdmeester [12] são prejudiciais, sendo recomendado, portanto, evitar longos períodos sentados, intercalando as tarefas que permitam a postura em pé, estática ou dinâmica. A postura sentada pode, ainda, ocasionar em diversos tipos de danos à saúde do trabalhador, sobretudo, o sistema músculo esquelético e o subsistema neural, que são formados pelas estruturas do sistema nervoso [13].

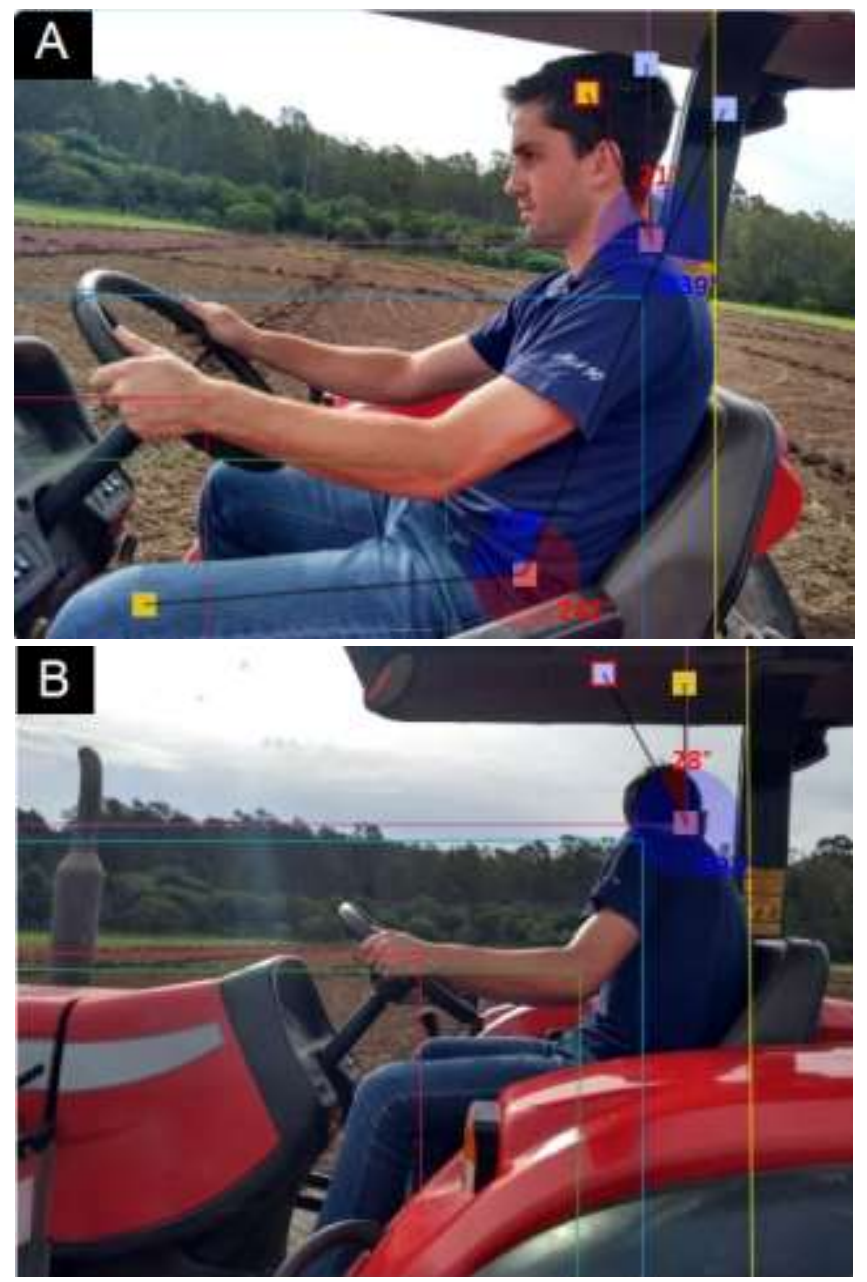

Figura 1 - Posições predominantes na operação de preparo de solo em várzea.

$\mathrm{Na}$ operação de máquinas agrícolas, a rotação do tronco para visualizar o implemento utilizado, pode provocar sobrecarga na coluna [3], resultando em dor e desconforto, especialmente nessa região. Conforme observado na Figura 1A, o operador mantém um ângulo de aproximadamente $118^{\circ}$ entre o tronco e os membros inferiores. Entretanto, segundo Guimarães [10], a angulação ideal para uma postura confortável, deve ser, necessariamente, maior que $90^{\circ}$ e menor que $110^{\circ}$. Assim, essa divergência pode estar agravando os sintomas de dor e desconfortos, apresentados pelo operador. 
Em relação à avaliação do número de viradas e do tempo de permanência na posição B, o operador apresentou extrema variação ao longo do tempo de trabalho, indicado pelo alto valor do coeficiente de variação de $296,29 \%$ e $381,23 \%$ respectivamente, Tabela 4 .

Tabela 4 - Avaliação de número de viradas do operador e tempo que permanece na posição B.

\begin{tabular}{ccc}
\hline Tempo (horas) & Número de viradas & $\begin{array}{c}\text { Tempo na posição B } \\
(\boldsymbol{\%})\end{array}$ \\
\hline $0-0,5$ & 32 & 24 \\
$0,5-1$ & 25 & 20 \\
$1-1,5$ & 18 & 16 \\
$1,5-2$ & 15 & 13 \\
\hline Média & 22,50 & 18,25 \\
\hline Desvio Padrão & 7,59 & 4,79 \\
\hline CV* (\%) & 296,29 & 381,23 \\
\hline
\end{tabular}

* $\mathrm{CV}=$ Coeficiente de variação.

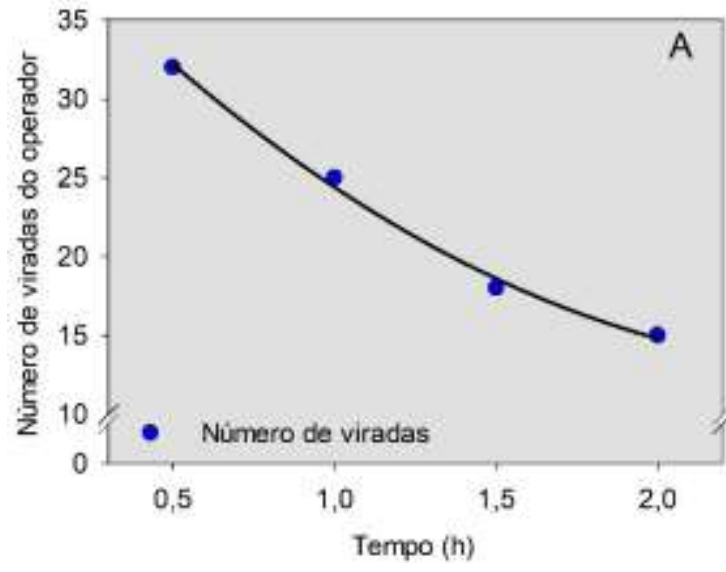

Na Figura 2 é apresentado o número de viradas do operador em relação ao tempo de observação (Figura 2A) e o tempo de permanência na postura rotacionada, também em comparação ao tempo de observação (Figura 2B). Ao analisar o número de viradas do tronco para visualizar o implemento na traseira do trator, é possível observar um comportamento inversamente proporcional em relação ao aumento do tempo (Figura 2A). Esse mesmo efeito ocorreu com o tempo em que o operador permanceceu na posição B. Ou seja, com o aumento da jornada de trabalho houve a redução no tempo de permanência de rotação do tronco (Figura $2 \mathrm{~B}$ ). Esse fato pode estar associado à fadiga no trabalho, visto que, quando considerado o tempo de $2 \mathrm{~h}$, o operador diminuiu para menos da metade o número de viradas, além de decair o tempo na posição B.

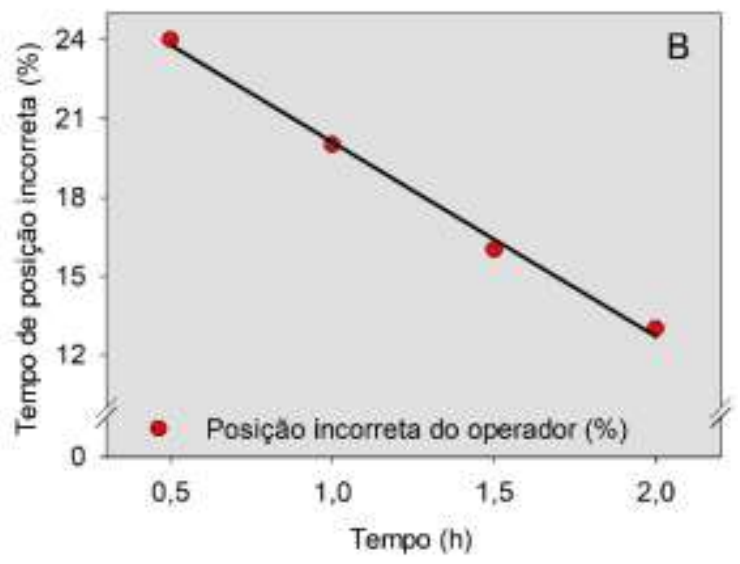

Figura 2 - Número de viradas para trás do operador (A) e tempo que o operador permanece na posição B (B).

Segundo Pinheiro; França [14], o caráter de alta repetitividade exigida pode determinar o aparecimento de fadiga nos trabalhadores, reduzindo a disposição, concentração e o rendimento operacional.

$\mathrm{Na}$ Tabela 5 é apresentada a sumarização dos resultados dos métodos posturais com base na posição B.

Tabela 5 - Sumarização dos resultados dos métodos $O W A S, R U L A$ e REBA baseada na posição $B$.

\begin{tabular}{ccc}
\hline Método & Categoria & Intervenção \\
\hline OWAS & 3 & São necessárias correções tão logo quanto possível. \\
\hline RULA & 3 & $\begin{array}{c}\text { Deve-se realizar uma investigação. Devem ser } \\
\text { introduzidas mudanças. }\end{array}$ \\
\hline REBA & $4-7$ & Necessária \\
\hline
\end{tabular}

Foi observado que, independentemente do método considerado, ao analisar a postura mais extrema empregada pelo operador (postura B), é necessário realizar intervenções em um futuro próximo. Nessa posição avaliada, o operador apresenta rotação do tronco, agravante que pode configurar-se enquanto decisivo para apresentar tal resultado.

$\mathrm{O}$ estudo que compreende as condições humanas e as condições de trabalho, em qualquer ambiente de trabalho, é de extrema importância, pois objetiva desenvolver e aperfeiçoar métodos e técnicas operacionais, para que sejam garantidas as condições mais seguras, confortáveis e saudáveis no ambiente de trabalho [3]. Ainda, segundo o mesmo autor, o conhecimento das condições de vida e a busca constante de sua melhoria influenciam 
diretamente na satisfação do trabalhador, levando ao aumento de produtividade e qualidade do trabalho.

Segundo Rozin [15], a melhoria dos conhecimentos em ergonomia é capaz de produzir novos conceitos de máquinas, fazendo com que os fabricantes passem a oferecer modelos de tratores agrícolas com uma melhor localização dos comandos de operação e instrumentos de controle.

Dessa forma, uma possível alternativa de projeto para solucionar a problemática da visada do operador para trás, poderia ser a utilização de uma câmera na traseira do trator, interligada a uma tela na cabine da máquina para acompanhar o implemento no decorrer da atividade. Outra alternativa seria a adaptação de um espelho próximo ao operador e que possibilitasse observar a operação sem a necessidade de rotacionar o tronco.

Projetos inadequados de máquinas, assentos ou bancadas de trabalho podem obrigar o trabalhador a usar posturas inadequadas e, se forem mantidas por um longo tempo, podem provocar fortes dores no conjunto de músculos solicitados em sua conservação [3].

\section{Conclusões}

A operação de preparo de solo em áreas de várzeas necessita de intervenção em curto prazo, indicado pelos métodos $O W A S, R U L A$ e REBA.

O número de viradas do tronco do operador para trás e o tempo em que o operador permanece nessa posição tendem a diminuir ao longo da atividade devido à fadiga ocasionada pelo trabalho.

Uma intervenção importante, seria o apoio do antebraço durante a tarefa, uma vez que isso não ocorre. Atitude que se tomada poderia diminuir eventuais dores e desconfortos.

\section{Agradecimentos}

À propriedade que concedeu infraestrutura para realização das atividades e ao Laboratório de Pesquisa e Desenvolvimento de Máquinas Agrícolas (LASERG) pelo auxílio.

\section{POSTURAL ANALYSIS OF AGRICULTURAL OPERATOR IN SOIL PREPARATION ACTIVITY IN VÁRZEA AREAS}

ABSTRACT:The work, in its most varied forms, can bring harmful consequences to people body, physical demands, efforts transmitted by the equipment and mainly by the posture necessary for the development of a certain activity. The objective of this work was to evaluate the postures performed during the working day of an agricultural tractor operator in soil preparation activity in a floodplain area. For the data collection, the activity was monitored in a rural property in Ivorá - RS, photographic records of the operator's postures were carried out during the daily working day, count of the number of turns of the operator behind and time that remained in that position. The postural analysis was performed using the OWAS, RULA and REBA methods through Ergolândia 6.0 software. The analyzes showed that the posture of rotation of the trunk back decreased during the workday, possibly due by the fatigue caused by the work. Also, the general analysis of the methods demonstrated the need for short-term ergonomic intervention in the soil tillage operation in floodplain areas.

Keywords: Ergonomics. Methods. Intervention.

\section{Referências}

[1] FILHO, P. F. S., et al. Avaliação dos níveis de vibração vertical no assento de um trator agrícola de pneus utilizando um sistema de aquisição automática de dados. Revista Árvore, Vol. 27, n. 6, p.887-895, 2003.

[2] SANTOS, G. O. Vibrações em operador de trator agrícola na operação de semeadura sob sistema plantio direto. 2017. 135 p. Tese (Doutorado em Engenharia Agrícola) - Universidade Federal de Santa Maria, Santa Maria, 2017.

[3] IIDA, I. Ergonomia; projeto e produção. São Paulo: Editora Edgard Blucher, 2016.

[4] PAUluK, D. MICHALOSKI, A. O. Análise ergonômica do trabalho nas atividades de preparo do solo com trator agrícola. Espacios, Vol. 37, p. 1-11, 2016.

[5] POSSEBOM, G. Comparação de métodos para avaliação postural em operação de máquinas agrícolas. 2018. 104 p. Dissertação (Mestrado em Engenharia Agrícola) - Universidade Federal de Santa Maria, Santa Maria, 2018.

[6] BAUMHARDT, U. B. Metodologia para concepção de cabines de máquinas agrícolas com enfoque na segurança e ergonomia. 2012. 259 p. Tese (Doutorado em Engenharia Agrícola) - Universidade Federal de Santa Maria. Santa Maria, 2012 .

[7] ASSOCIAÇÃO BRASILEIRA DE ERGONOMIA. ABERGO. Disponível em: <http://www.abergo.org.br/internas.php?pg=o_que_e_ergonomia>. Acesso em $15 / 05 / 2018$. 
[8] SANTOS, N.; FIALHO, F. Manual de análise ergonômica do trabalho. Curitiba: Genesis. 2 ed. 1997.

[9] SANTOS, H. G., et al. Embrapa: Sistema Brasileiro de Classificação de Solos. $3^{\text {a }}$ ed. Brasília, 2013. 353p.

[10] MCATAMNEY, L.; CORLETT, N. Rapid Upper Limb Assessment (RULA). In N. Stanton, A. Hedge, K. Brookhuis, E. Salas \& H. Hendrick (Eds.), Handbook of Human factors and Ergonomics Methods. 2005.

[11] de GUIMARÃES B. M., et al. Análise da carga de trabalho de analistas de sistemas e dos distúrbios osteomusculares. Fisioterapia em Movimento, Vol. 24, p. 115-124, 2011.

[12] NARIMOTO, L. R. O trabalho dos operadores de máquinas colhedoras de cana-de-açúcar: uma abordagem ergonômica. 2012. 186 p. Dissertação (Mestrado em Engenharia de Produção) - Universidade Federal de São Carlos, 2012.

[13] DUL, J.; WEERDMEESTER, B.; IIDA, I. Ergonomia prática. São Paulo: Edgard Blücher, 2004. 137p.

[14] MARQUES, N. R.; HALLAL, C. Z.; GONÇALVES, M. Características biomecânicas, ergonômicas e clínicas da postura sentada: uma revisão. Fisioterapia e Pesquisa, Vol. 17, p. 270-276, 2010.

[15] PINHEIRO, A. K. S.; FRANÇA, M. B. A. Ergonomia aplicada à anatomii)a e fisiologia do trabalhador. Goiânia: AB Ed., 2006. 165p.

[16] ROZIN, D. et al. Conformidades dos comandos de operação de tratores agrícolas nacionais com a norma NBR ISSO 4253. Revista Brasileira de Engenharia Agrícola e Ambiental, Campina Grande, Vol. 14, p. 1014-1019, set. 2010. 